\section{EuroGentest patient information leaflets: a free resource available in over 20 languages}

European Journal of Human Genetics (2009) 17, 732; doi:10.1038/ejhg.2009.20; published online 4 March 2009

Research into the quality of written patient information about genetic testing across Europe has revealed that information often fails to provide a comprehensive discussion of key issues. ${ }^{1}$ Pre-written information leaflets, found to be more comprehensive than personal letters written by clinicians, are also not routinely available through genetic clinics.

In response to these findings, the EuroGentest project, an EU-funded Network of Excellence, has developed a series of patient information leaflets for patients and families related to genetics and genetic testing. The topics and content of these leaflets were developed by both genetic professionals and an 'expert' group of patient representatives from across Europe. The English-version leaflets were validated by a panel of patient group representatives from across the United Kingdom to ensure readability. Patient groups also helped select the diagrams and illustrations to be used in the leaflets.

Eleven leaflets have so far been developed, with another four currently in process. The leaflets have been translated into numerous languages spoken across Europe, including ethnic minority languages. The leaflets will be available in over 20 languages by the end of the 2009. Translations have been done by billingual genetic health professionals and $\mathrm{PhD}$ genetics students to ensure the information is relevant and correct for that country, the translations are of good quality, and medical explanations are translated clearly and correctly.

The titles of the 11 leaflets currently available are:

- What is a Genetic Test?

- Some Information about your Genetic Appointment

- The Amniocentesis

- The CVS Test
- Recessive Inheritance

- Dominant Inheritance

- X-linked Inheritance

- Chromosome Changes

- Chromosome Translocations

- Frequently Asked Questions about Genetic Testing

- Genetic Glossary

The leaflets are freely available to download in a range of languages from the following websites:

http://www.eurogentest.org/patients

http://www.eshg.org (Patient Information link)

The titles of the new leaflets currently in process are:

- What Happens in the Genetics Laboratory?

- Predictive Testing (cancer)

- Predictive Testing (non-cancer)

- Carrier Testing

These will be translated and made available on the EuroGentest and ESHG websites towards the end of 2009.

The aim is that clinicians will print and routinely provide these leaflets to patients and families. We hope that both clinicians and patients will find them to be a useful and informative resource.

\section{Acknowledgements}

The authors wish to thank all those patients representatives and translators who have kindly given up their time to help with this work. Without their dedication and hard work, these leaflets would not have been possible.

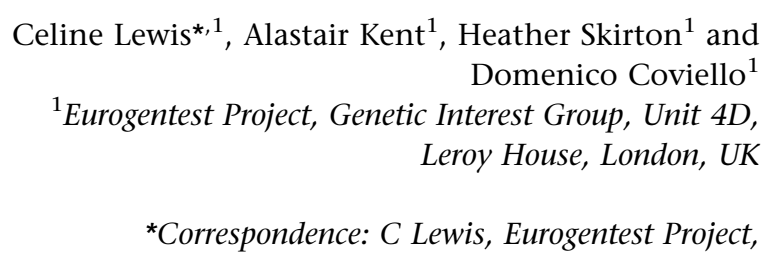
Genetic Interest Group, Unit 4D, Leroy House, 436 Essex Road, London N1 3QP, UK. Tel: + 440207704 3141; Fax: 440207359 447; E-mail: celine@gig.org.uk

\footnotetext{
Reference

1 Lewis C, Mehta P, Kent A, Skirton H, Coviello D: An assessment of written patient information provided at the genetic clinic and relating to genetic testing in seven European countries. Eur J Hum Genet 2007; 15: 1012-1022.
} 